\title{
TDS EVALUATION OF THE HYDROGEN TRAPPING CAPACITY OF NbC PRECIPITATES
}

\author{
E. WALLAERT \\ Department of Materials Science \\ and Engineering, Ghent University \\ (UGent), Technologiepark 903, B- \\ 9052 Ghent, Belgium
}

\section{B. PIETERS \\ Department of Materials Science and Engineering, Ghent University (UGent), Technologiepark 903, B- 9052 Ghent, Belgium}

\section{K. VERBEKEN}

Department of Materials Science and Engineering, Ghent University (UGent), Technologiepark 903, B9052 Ghent, Belgium

\author{
T. DEPOVER \\ Department of Materials Science \\ and Engineering, Ghent University \\ (UGent), Technologiepark 903, B- \\ 9052 Ghent, Belgium
}

\author{
M. A. ARAFIN \\ ArcelorMittal GlobalR\&D Gent, \\ Technologiepark 935, B-9052 \\ Zwijnaarde, Belgium
}

\begin{abstract}
In this work, ferritic steel containing $\mathrm{NbC}$ precipitates was investigated. The materials were subjected to various heat treatments, giving rise to different precipitate size distributions as determined by TEM (Transmission Electron Microscopy). The steels were hydrogen charged both electrochemically and from a gaseous phase, followed by multiple TDS (Thermal Desorption Spectroscopy) measurements. Electrochemical charging gives rise to a low temperature peak $\left(80-120^{\circ} \mathrm{C}\right)$, originating from the hydrogen trapped near grain boundaries and at $\mathrm{NbC}$ precipitates, having activation energy ranging between 24 and $44 \mathrm{~kJ} / \mathrm{mol}$. Gaseous charging leads to a high temperature TDS peak $\left(450-550^{\circ} \mathrm{C}\right)$, which indicates that hydrogen is trapped by incoherent $\mathrm{NbC}$ precipitates, with activation energy ranging between 62 and $71 \mathrm{~kJ} / \mathrm{mol}$.
\end{abstract}

\section{INTRODUCTION}

Although the first detrimental effects of hydrogen on the mechanical properties of iron and steels were described by Johnson in 1875, many features of the involved mechanisms are still poorly understood and are the subject of debate [1]. As a result of the rising demand for high strength steels, since these materials are known to be sensitive to the harmful consequences of hydrogen, an increasing interest for hydrogen embrittlement research arose.

The introduction of carbides as hydrogen trapping sites in steels is an often quoted approach to reduce the amount of diffusible hydrogen in the steels and, as such, reduce susceptibility towards hydrogen damage [2]. Niobium, next to titanium and vanadium, is a carbide forming alloying element [3]. However, the 
interaction between the $\mathrm{NbC}$ precipitates and hydrogen has rarely been evaluated in detail.

Tsuzaki and co-workers observed the presence of hydrogen near semicoherent $\mathrm{NbC}$ precipitates, having a disc shape with $5 \mathrm{~nm}$ length and $2 \mathrm{~nm}$ thickness, after electrochemical charging using small-angle neutron scattering (SANS) [4]. Earlier results of Gehrmann et al already claimed, based on hydrogen permeation experiments, that incoherent $\mathrm{NbC}$ and $\mathrm{NbN}$ precipitates were deep hydrogen traps [5]. NbC precipitates are considered to consist of several hydrogen trapping sites with various activation energies, such as the precipitate-ferrite interface, the coherency strain region surrounding the precipitate (misfit dislocations) and the crystallographic defects inside the precipitate [6]. The hydrogen trapping capacity is argued to be higher than for TiC and VC precipitates [7].

In this work, an alloy containing $\mathrm{NbC}$ precipitates in a ferritic matrix was investigated. The samples were subjected to different heat treatments, giving rise to different precipitate size distributions as determined by TEM analysis. The $\mathrm{NbC}$ precipitates were hydrogen charged both electrochemically and from gaseous $\mathrm{H}_{2}$, followed by multiple TDS measurements.

\section{EXPERIMENTAL \\ Materials}

The composition of the used lab cast material is given in Table 1 and was chosen for stoichoimetric reasons to promote the formation of $\mathrm{NbC}$ precipitates. This material was produced in a Pfeiffer VSG100 vacuum melt and cast unit, operated under a protective argon gas atmosphere. The samples were processed by hot and cold rolling the cast blocks to sheets with $1.7 \mathrm{~mm}$ thickness.

\begin{tabular}{llllllll}
\hline & $\mathbf{C}$ & $\mathbf{M n}$ & $\mathbf{S i}$ & $\mathbf{N b}$ & $\mathbf{T i}$ & $\mathbf{N}$ & Others \\
\hline $\mathbf{C O 8 0}(\mathbf{N b}+\mathbf{C})$ & 0.013 & 0.0049 & 0.0054 & 0.1 & 0.0092 & 0.0007 & $\mathrm{P}, \mathrm{S}, \mathrm{Al}$ \\
\hline
\end{tabular}

Table 1: Chemical composition of the material used (weight percent).

In order to promote the formation of different precipitate size distributions, the material was subjected to three different heat treatments, as summarized in Figure 1. Two materials, CO80-1 and CO80-2, were treated at $1200^{\circ} \mathrm{C}$ for 30 minutes and at $800^{\circ} \mathrm{C}$ for 10 and 120 minutes, respectively. The third material, $\mathrm{CO} 80-\mathrm{H}_{2}$, was heat treated under $\mathrm{H}_{2}$ atmosphere at $800^{\circ} \mathrm{C}$ for 58 hours. After the heat treatment, disc-shaped samples with a diameter of $20 \mathrm{~mm}$ were punched and ground to a thickness of $1 \mathrm{~mm}$. Figure 1 also shows the optical micrographs of the three materials. All three consist of a ferritic matrix, in the CO80-1 and CO80-2 materials grain growth is clearly observed. On the contrary, due to the lower temperature used in the heat treatment of $\mathrm{CO} 80-\mathrm{H}_{2}$, grain growth in this material was limited as the present $\mathrm{NbC}$ precipitates did not dissolve and as such prevented grain growth. 

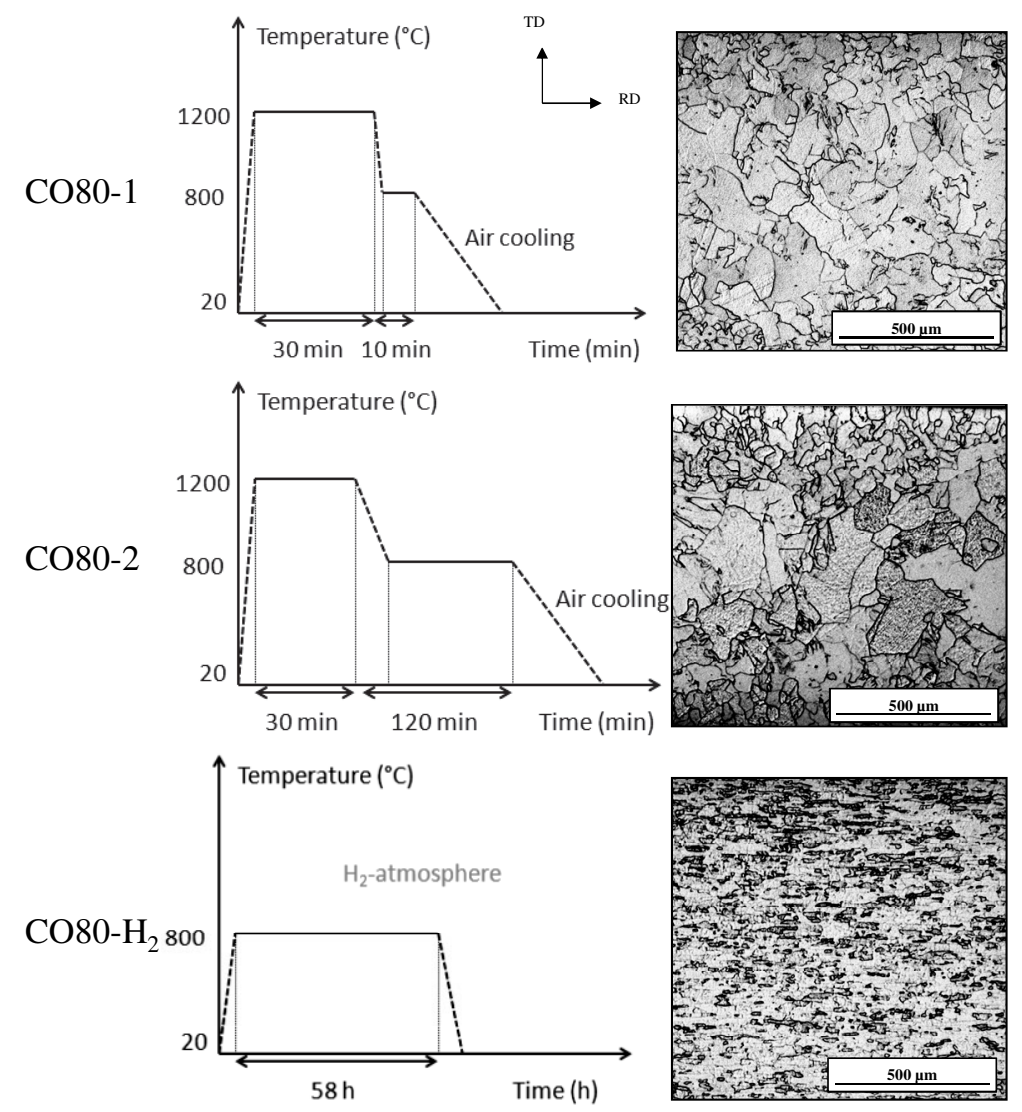

Figure 1: Temperature-time graphs and optical microscope pictures of the three materials used.

\section{STEM measurements, hydrogen charging and TDS measurements}

In order to verify the presence of $\mathrm{NbC}$ precipitates in the steel matrix, STEM (Scanning Transmission Electron Microscopy) analysis, using a JEM2200FS, as well as EDX (Energy Dispersive X-Ray) spectroscopy was performed. The thin foil samples were prepared by grinding and polishing the samples to a thickness below $100 \mu \mathrm{m}$. Afterwards, they were electro-polished, using a TenuPol-5 electro-polishing unit of Struers, in a $10 \%$ perchloric acid and $90 \%$ acetic acid solution.

The CO80-1 and CO80-2 samples were electrochemically charged for one hour, using a $0.5 \mathrm{M}$ sulfuric acid aqueous solution containing $1 \mathrm{~g} / \mathrm{L}$ thiourea and with a current density of $0.8 \mathrm{~mA} / \mathrm{cm}^{2}$. These parameters are based on results of a previous study [8]. The $\mathrm{CO} 80-\mathrm{H}_{2}$ samples were already hydrogen charged during the heat treatment. This charging procedure already demonstrated its effectiveness for $\mathrm{TiC}$ precipitates as was shown by Pérez Escobar et al [9].

The charged samples were cleaned with distilled water and isopropanol and then inserted in the TDS chamber. The vacuum pump is subsequently initiated 
and after $1 \mathrm{~h}$ the vacuum level is low enough $\left(<0.35 \times 10^{-3} \mathrm{~Pa}\right)$ to be able to start the test. Similarly to our previous work, the activation energy was determined by performing TDS tests using four different heating rates, namely 3.33, 6.66, 13.33 and $20{ }^{\circ} \mathrm{C} / \mathrm{min}$ [10]. Subsequently, a deconvolution was applied and the Lee et al method was used to correlate peak temperatures with activation energies [11-13]. Equation 1 is a simplification of the original formula of Kissinger [14].

$$
\frac{d \ln \left(\phi / T_{\text {max }}^{2}\right)}{d\left(1 / T_{\max }\right)}=-\frac{E_{A}}{R}
$$

Where $\phi$ is the heating rate $(\mathrm{K} / \mathrm{s}), \mathrm{T}_{\max }(\mathrm{K})$ the TDS peak temperature, $\mathrm{E}_{\mathrm{A}}$ $(\mathrm{J} / \mathrm{mol})$ is the activation energy for hydrogen desorption of the specific trap associated with $\mathrm{T}_{\max }$ and $\mathrm{R}\left(\mathrm{J} \cdot \mathrm{K}^{-1} \cdot \mathrm{mol}^{-1}\right)$ is the universal gas constant.

\section{RESULTS AND DISCUSSION \\ CO80-1}

The $\mathrm{NbC}$ precipitates present in the CO80-1 material have a length of about $10 \mathrm{~nm}$ (see Figure 2). They were found to be round, rectangular or ellipsoidal.
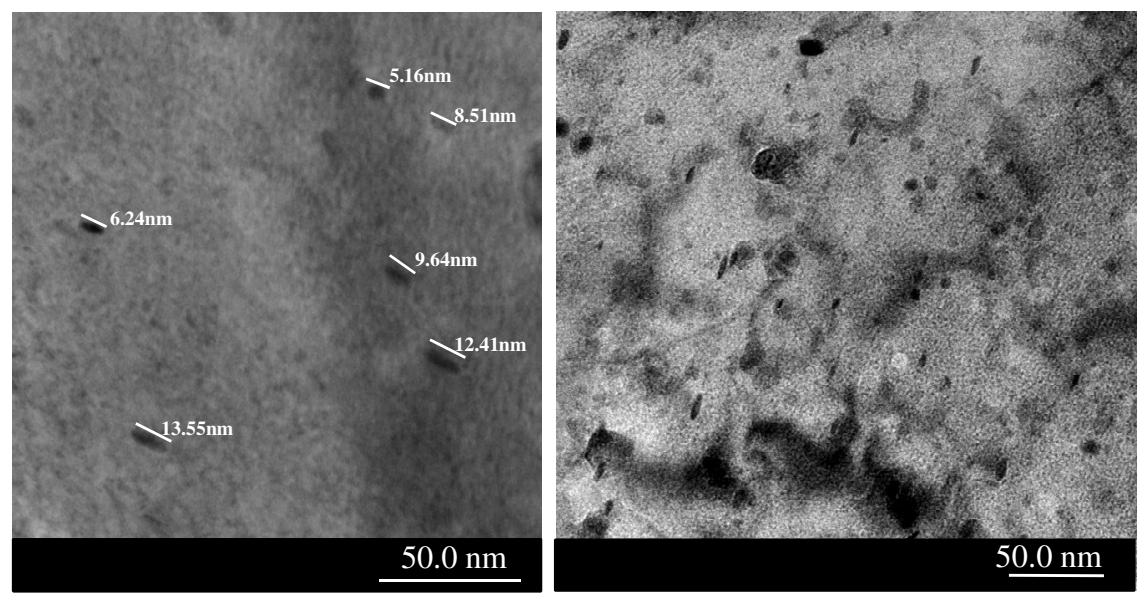

Figure 2: Bright field STEM image of CO80-1 thin foil.

The TDS spectrum is deconvoluted into three separate peaks (see Figure 3). The activation energies for the three peaks are $27 \pm 5,24 \pm 5$ and $24 \pm 5 \mathrm{~kJ} / \mathrm{mol}$, respectively. The first hydrogen desorption peak is believed to be attributable to hydrogen trapped at grain boundaries. This value is well within the known range of desorption energies for grain boundaries, 18 to $59 \mathrm{~kJ} / \mathrm{mol}$ [15-17]. It also makes up the largest part of the total hydrogen desorption. Hydrogen trapping at dislocations is more unlikely in the present case, as was demonstrated by Pérez Escobar et al [18]. The latter two peaks have similar activation energies and are assumed to be produced by the hydrogen trapped at the $\mathrm{NbC}$ precipitates. As was argued by Wei et al, the hydrogen is trapped in the core of the misfit 
dislocations surrounding the broad interface of the small $\mathrm{NbC}$ precipitates [6-7, 19]

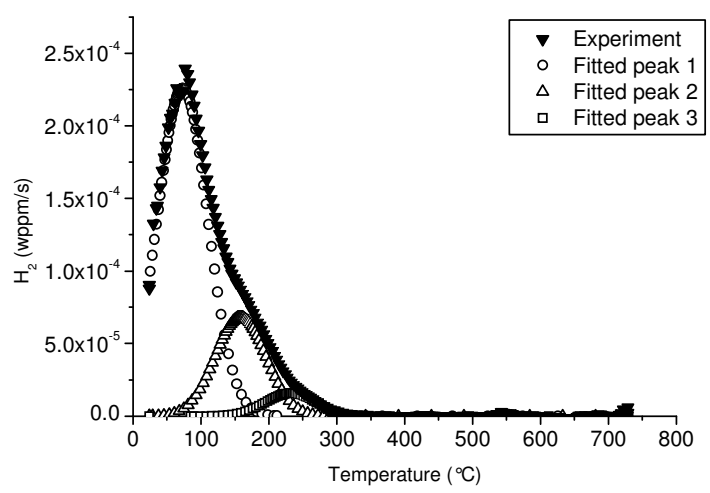

Figure 3: TDS spectrum of the CO80-1 material after electrochemical charging, heating rate $6.66^{\circ} \mathrm{C} / \mathrm{h}$.

\section{CO80-2}

The TEM images of the CO80-2 material show two types of precipitates, smaller ones with a length of about $10 \mathrm{~nm}$ and larger ones with a length between 85 and $195 \mathrm{~nm}$ (see Figure 4).
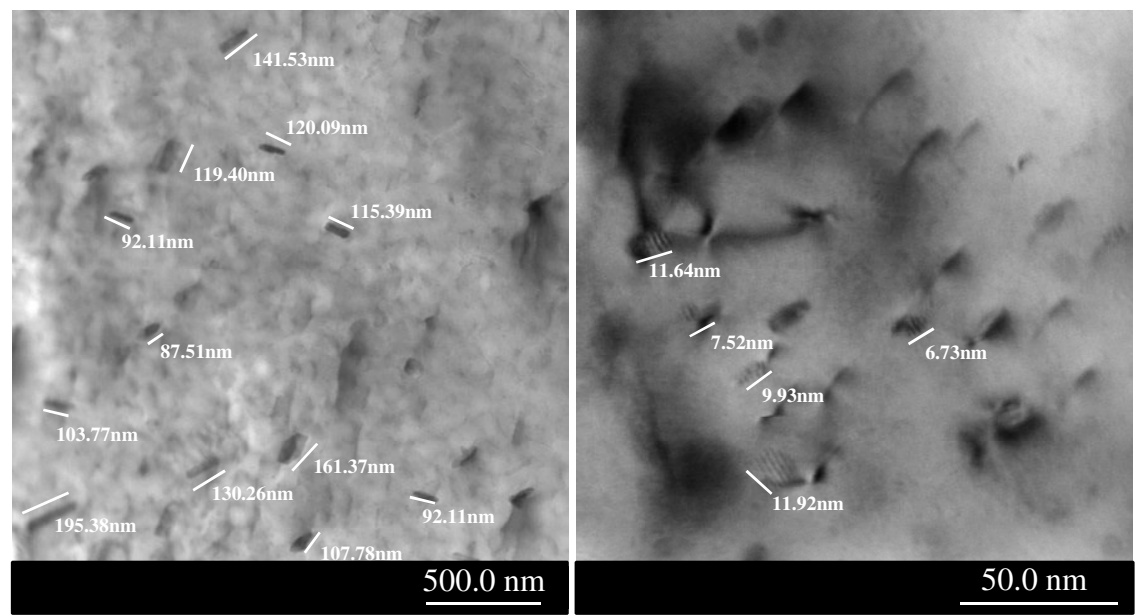

Figure 4: Bright field STEM image of CO80-2 thin foil.

The corresponding TDS spectrum is deconvoluted into four separate peaks (see Figure 5). The activation energies for these peaks are $30 \pm 0.4,33 \pm 2,40 \pm 3$ and $44 \pm 1 \mathrm{~kJ} / \mathrm{mol}$, respectively. The first peak could again be correlated with hydrogen desorption from grain boundaries. The corresponding activation energy is similar to the one obtained for the CO80-1 material, which has a comparable grain size (see Figure 1). The second peak is probably due to the 
hydrogen trapped at the smaller precipitates $(10 \mathrm{~nm})$, which are also present in the CO80-1 material. In this case only one peak is observed, however the activation energy is in the same range. The other two peaks likely correspond to $\mathrm{NbC}$ precipitates having larger dimensions $(85-195 \mathrm{~nm})$. The phase boundary coherency is known to decrease with precipitate size. Consequently, an increase in incoherency and an increase in the corresponding activation energy is expected as was already stated by Wei et al for TiC precipitates [19]. The present, higher hydrogen desorption energies, ranging from 40 to $44 \mathrm{~kJ} / \mathrm{mol}$, confirm this statement.

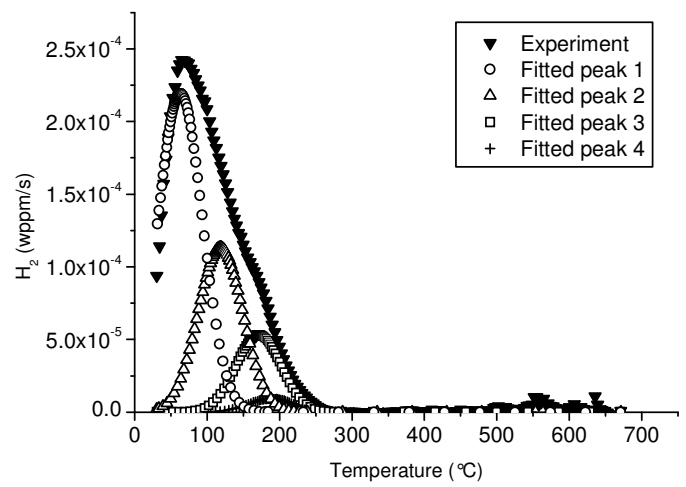

Figure 5: TDS spectrum of the CO80-2 material after electrochemical charging, heating rate $6.66^{\circ} \mathrm{C} / \mathrm{h}$.

\section{$\mathrm{CO} 80-\mathrm{H}_{2}$}

TEM analysis of the $\mathrm{CO} 80-\mathrm{H}_{2}$ material shows three types of precipitates: very small ones of only a few nanometers, precipitates ranging between 50 and $100 \mathrm{~nm}$ and precipitates of several hundreds of nanometers (see Figure 6).The precipitates smaller than 1-3 nm are likely to have a higher degree of coherency, as was also demonstrated by Wei and Tsuzaki for TiC precipitates [19].
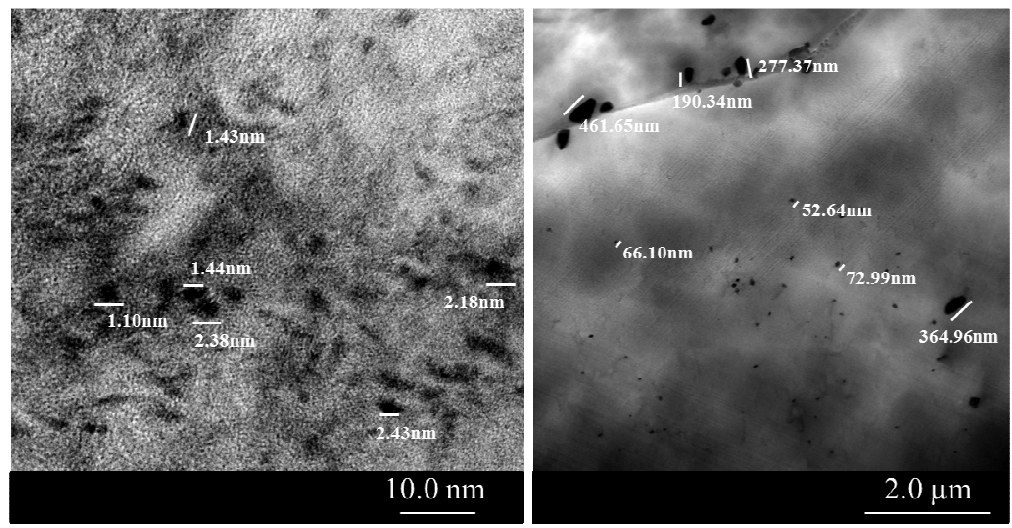

Figure 6: Bright field STEM image of $\mathrm{CO} 80-\mathrm{H}_{2}$ thin foil. 
The TDS spectra of gaseous charged $\mathrm{CO} 80-\mathrm{H}_{2}$ samples do not show low temperature peaks, since gaseous charging was performed at temperatures significantly higher than the typical temperature at which the low temperatures peaks occur. Electrochemical charging, which generates the low temperature peak, was not applied after gaseous charging on this material. As such, no desorption energy, for the hydrogen that was trapped in the grain boundaries, could be calculated. A high temperature peak can be clearly observed (see Figure 7). This peak is deconvoluted into two peaks and calculation of the desorption energy gave values of 63 and $71 \mathrm{~kJ} / \mathrm{mol}$. The interaction of hydrogen with these precipitates might be similar as for TiC precipitates [19]. Hydrogen is considered to be trapped inside the carbon vacancies present in the incoherent precipitates. Gaseous charging at elevated temperatures is required to supply the necessary energy for the hydrogen to enter this hydrogen trap. It is assumed that the two different desorption peaks can be attributed to the bimodal size distribution of the precipitates that tends to be present in the material.

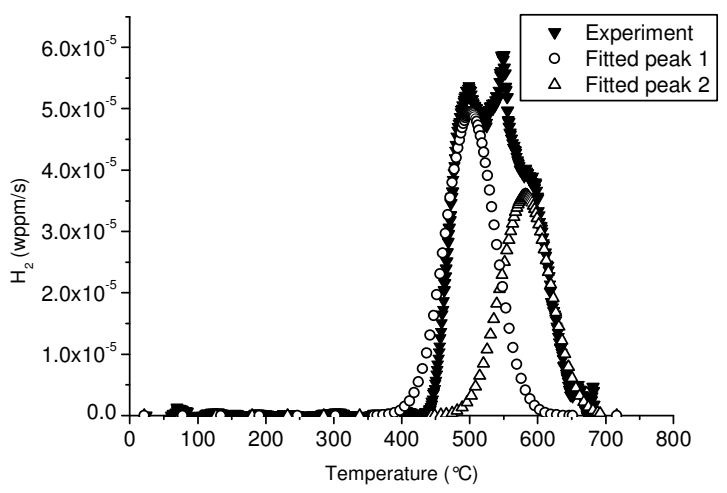

Figure 7: TDS spectrum of the $\mathrm{CO} 80-\mathrm{H}_{2}$ material, heating rate $6.66{ }^{\circ} \mathrm{C} / \mathrm{h}$.

\section{CONCLUSIONS}

TDS measurements were performed on a lab cast material containing $\mathrm{NbC}$ precipitates. Electrochemical charging gave rise to a low temperature peak (80$120^{\circ} \mathrm{C}$ ), originating from the hydrogen trapped near grain boundaries, with activation energy ranging between 27 and $30 \mathrm{~kJ} / \mathrm{mol}$, and at $\mathrm{NbC}$ precipitates, 24 - $44 \mathrm{~kJ} / \mathrm{mol}$. Charging in a gaseous environment gave rise to a high temperature TDS peak $\left(450-550^{\circ} \mathrm{C}\right)$, which was attributed to the presence of incoherent $\mathrm{NbC}$ precipitates, the activation energy ranged between 62 and $71 \mathrm{~kJ} / \mathrm{mol}$. Gaseous charging is considered to be necessary in order to provide the required energy to trap the hydrogen in the $\mathrm{C}$ vacancies of the precipitates. No low temperature peak is observed, since no electrochemical charging was performed. 


\section{ACKNOWLEDGEMENTS}

The authors wish to thank the Special Research Fund (BOF), Ghent University (BOF10/ZAP/121) and the Agency for Innovation by Science and Technology in Flanders (IWT) for support (Project nr SB111205).

The authors also acknowledge the technicians and staff working at the hydrogen laboratory at OCAS (ArcelorMittal R\&D Gent) and the technical staff from the Department Materials Science and Engineering, Ghent University, for their help with the experiments and sample preparation.

\section{REFERENCES}

[1] Johnson, W.H., 1875, "On some remarkable changes produced in iron and steel by the action of hydrogen acids," Proceedings of the Royal Society of London, 23A, pp. 168-179.

[2] Duprez, L., Verbeken, K., and Verhaege, M., 2008, "Effect of hydrogen on the mechanical properties of multiphase high strength steels," Proceedings of the 2008 international hydrogen conference, B.P. Somerday et al., eds., ASM International, pp. 62-69.

[3] Vervynckt, S., Verbeken, K., Lopez, B., and Jonas, J.J., 2012, "Modern HSLA steels and the role of the non-recrystallization temperature," International Materials Review, 57, pp. 187-207.

[4] Ohnuma, M., Suzuki, J.I., Wei, F.G., and Tsuzaki, K., 2008, "Direct observation of hydrogen trapped by $\mathrm{NbC}$ in steel using small-angle neutron scattering," Scripta Materialia, 58, pp. 142145.

[5] Gehrmann, F., 1995, "The effects of the nitrides and carbides of V, Nb and Ti on the diffusion and dissolution of hydrogen in iron," Hydrogen transport and cracking in metals, A. Turnbull, eds., London, pp. 216-226.

[6] Wei, F.G., and Tsuzaki, K., 2008, "Hydrogen trapping character of nano-sized NbC precipitates in tempered martensite," Proceedings of the 2008 international hydrogen conference, B.P. Somerday et al., eds., ASM International, pp. 456-463.

[7] Wei, F.G., Hara, T., and Tsuzaki, K., 2008, "Nano-precipitates design with hydrogen trapping character in high strength steels," Proceedings of the 2008 international hydrogen conference, B.P. Somerday et al., eds., ASM International, pp. 448-455.

[8] Pérez Escobar, D., Miñambres, L., Duprez, L., Verbeken, K., and Verhaege, M., 2011, "Internal and surface damage of multiphase steels after electrochemical hydrogen charging," Corrosion Science, 53, pp. 3166-3176.

[9] Pérez Escobar, D., Verbeken, K., Duprez, L., and Verhaege, M., 2012, "On the methodology of Thermal Desorption Spectroscopy to evaluate hydrogen embrittlement," Materials Science Forum, 706-709, pp. 2354-2359.

[10] Pérez Escobar, D., Duprez, L., Verbeken, K. and Verhaege, M., 2012, "Evaluation of hydrogen trapping in high strength steels by Thermal Desorption Spectroscopy," Materials Science and Engineering A, 551, pp. 50-58.

[11] Lee, S.M. and Lee J.Y., 1986, "The trapping and transport phenomena of hydrogen in nickel," Metallurgical Transactions A, 17A, pp. 181-187.

[12] Lee, J.Y., and Lee, S.M., 1986, "Hydrogen trapping phenomena in metals with bcc and fcc crystal structures by the desorption thermal-analysis technique," Surface and Coatings Technology, 28, pp. 301-314.

[13] Lee, J.L., and Lee, J.Y., 1983, “ Hydrogen trapping in AISI-4340 steel,” Metal Science, 17, pp. 426-432.

[14] Kissinger, H.E., 1957, "Reaction kinetics in differential thermal analysis," Analytical Chemistry, 29, pp. 1702-1706.

[15] Choo, W.Y., and Lee, J.Y., 1982, "Thermal analysis of trapped hydrogen in pure iron," Metallurgical Transactions A-Physical, 13A, pp. 135-140.

[16] Kumnick, A.J., and Johnson, H.H., 1980, "Deep trapping states for hydrogen in deformed iron," Acta Metallurgica, 28, pp. 33-39. 
[17] Asaoka, T., Daggbert, C., Aucouturier, M., and Galland, J., 1977, "Quantitative study on capture of hydrogen in ferrite $\mathrm{Fe}-0.15 \%$-Ti using high-resolution autoradiography and degassing at different temperatures," Scripta Metallurgica, 11, pp. 467-472.

[18] Pérez Escobar, D., Depover, T., Duprez, L., Verbeken, K., and Verhaege, M., 2012, "Combined thermal desorption spectroscopy, differential scanning calorimetry, scanning electron microscopy and X-ray diffraction study of hydrogen trapping in cold deformed TRIP steel," Acta Materialia, 60, pp. 2593-2605.

[19] Wei, F.G., and Tsuzaki, K., 2006, "Quantitative analysis on hydrogen trapping of TiC particles in steel," Metallurgical and Materials Transactions A, 37A, pp. 331-353. 
